\title{
DESENVOLVIMENTO DE METODOLOGIA PARA DETERMINAÇÃo DE PIRETROIDES EM MANTEIGA
}

Deyse de Brito Marthe, Leila Moreira Bittencourt, Maria Eliana Lopes Ribeiro de Queiroz* e Antônio Augusto Neves

Departamento de Química, Universidade Federal de Viçosa, 36570-000 Viçosa - MG, Brasil

Recebido em 20/8/09; aceito em 19/1/10; publicado na web em 3/5/10

\begin{abstract}
DEVELOPMENT OF A METODOLOGY FOR ANALYSIS OF PYRETHROIDS IN BUTTER. The objective of this study was to evaluate the use of the matrix solid-phase dispersion technique associated with purification at low temperature for the determination of pyrethroids in butter. Evaluated parameters included: sample/adsorbent ratio, type of adsorbent and extractor solvent. The optimized method was validated based on predetermined requirements. The detection limits of the pyrethroids cypermethrin and deltamethrin were 0.082 and $0.11 \mu \mathrm{g} \mathrm{g}^{-1}$, and quantification limit were 0.28 and $0.32 \mu \mathrm{g} \mathrm{g}^{-1}$, respectively, with extraction percentages near $90 \%$ and coefficients of variation less than of $10 \%$.
\end{abstract}

Keywords: pyrethroid; butter; gas chromatography.

\section{INTRODUÇÃO}

O leite possui um conjunto de nutrientes que desempenham papel importante no funcionamento do corpo humano, sendo considerado um dos alimentos essenciais ao organismo. Por ser fonte de proteína, cálcio e outros minerais na forma biodisponível faz parte de uma dieta equilibrada e saudável. ${ }^{1}$ Além de ser um alimento de baixo custo e, portanto, de fácil acesso, o leite e seus derivados também participam da composição de vários alimentos presentes na dieta da população brasileira. A qualidade desses produtos pode ser prejudicada pela presença de carrapaticidas. A utilização indiscriminada dessas substâncias pode contaminar o leite e seus derivados com resíduos acima do limite máximo permitido pela legislação. Esses resíduos são originados do uso de rações e pastagens contaminadas, ou especialmente do tratamento dos animais com carrapaticidas para combater ectoparasitas. ${ }^{2}$

Os carrapaticidas se classificam como "sistêmicos" (atuando pela circulação sanguínea) ou como "de contato" aplicados por banhos de pulverização, imersão ou por spray no pelo, encontrando-se no mercado de diversas formas, como os piretroides (ex. Butox, Bayticol, Ultimate). ${ }^{3}$

Os piretroides são inseticidas de origem vegetal, amplamente utilizados devido a sua alta eficácia contra insetos e baixa toxidade para mamíferos e pássaros. Mesmo o piretroide sendo facilmente biotransformado e possuindo uma rápida excreção em mamíferos, ${ }^{4}$ ao ser aplicado sobre o corpo do animal consegue ultrapassar a barreira do couro animal e entrar na corrente sanguínea. Os piretroides podem ser eliminados do organismo pelos rins e pelas glândulas mamárias, porém o processo para uma completa eliminação leva aproximadamente 35 dias. Nos primeiros 14 dias, a quantidade de resíduos encontrados é suficiente para causar uma possível intoxicação. ${ }^{5}$ Dentre os piretroides, os mais utilizados como carrapaticidas são a cipermetrina e a deltametrina (Figura 1).

Normalmente, estes compostos são aplicados em baixas doses, de modo que, quando utilizados de maneira correta, os resíduos presentes em alimentos são encontrados em baixas concentrações, sendo que o limite máximo permitido para leite é de $0,05 \mu \mathrm{g} \mathrm{g}^{-1}$. Em função do caráter lipofílico destes compostos levantou-se a hipótese que estes poderiam se concentrar nos derivados do leite em matrizes mais gordurosas, como a manteiga e o queijo.

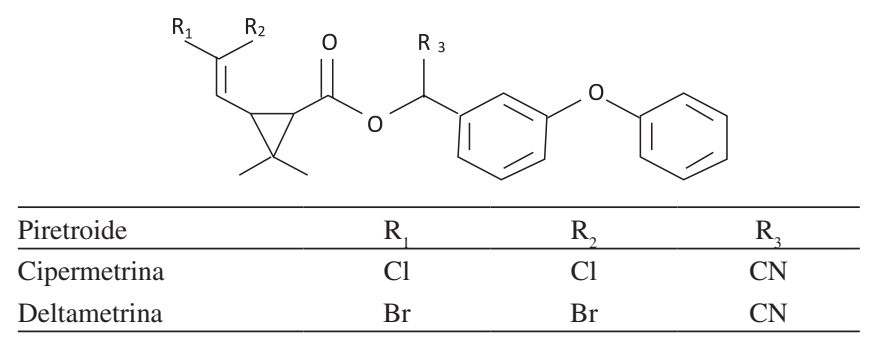

Figura 1. Fórmula estrutural básica de piretroides sintéticos e seus radicais

Alimentos com resíduos de agrotóxicos e que contêm teores de gordura superiores a $2 \%$ podem ser extraídos utilizando a técnica de extração líquido-líquido, para isolar a fração lipídica. ${ }^{6}$ Normalmente, as técnicas empregadas para extração de compostos químicos de matrizes gordurosas e alimentos são trabalhosas e envolvem grandes quantidades de solventes e etapas de purificação ${ }^{6}$ que podem levar à perda dos componentes de interesse. ${ }^{7}$

Visando reduzir etapas de purificação, Goulart ${ }^{5}$ e Goulart et al. ${ }^{8}$ adaptaram uma metodologia simples, para análise de deltametrina e cipermetrina em leite, baseando-se no método empregado por Mcculley e Mckinley ${ }^{9}$ para análise de organoclorados em óleo. No método chamado extração líquido-líquido com purificação em baixa temperatura (ELL-PBT), os piretroides foram determinados em leite sem a necessidade de etapas de purificação. Vieira et al. ${ }^{10}$ aplicaram esta técnica para extração simultânea de cipermetrina, deltametrina, $\lambda$-cialotrina e permetrina em amostras de água. Esta técnica aplicada em amostras sólidas é denominada extração sólido-líquido com partição em baixa temperatura (ESL-PBT).

Outra técnica bastante empregada em análise de resíduos em alimentos semissólidos e sólidos é a dispersão de matriz em fase sólida (DMFS), pois agrupa em uma única etapa a extração e purificação dos extratos. ${ }^{11}$ A amostra sólida ou semissólida é dispersa em um adsorvente, sendo os analitos extraídos desta mistura com um solvente adequado e analisados por métodos cromatográficos. ${ }^{12}$

Procurou-se avaliar neste trabalho a técnica DMFS associada à técnica ESL-PBT para a determinação dos piretroides cipermetrina e deltametrina em manteiga por cromatografia gasosa com detecção por captura de elétrons (CG/ECD). 


\section{PARTE EXPERIMENTAL}

\section{Reagentes, sorventes e soluções}

A partir de padrões de cipermetrina $(92,4 \% \mathrm{~m} / \mathrm{m}$ - Chem Service) e deltametrina $(99,0 \% \mathrm{~m} / \mathrm{m}$ - Chem Service) foi preparada uma solução estoque contendo ambos os piretroides na concentração de $500,0 \mathrm{mg} \mathrm{L}^{-1}$, utilizando acetonitrila (Mallinckrodt/HPLC) como solvente. As soluções de trabalho foram preparadas pela diluição da solução estoque utilizando-se acetonitrila.

Uma solução padrão de bifentrina (92,2\% m/m - FMC do Brasil) $50,0 \mathrm{mg} \mathrm{L}^{-1} \mathrm{em}$ acetonitrila também foi preparada como padrão interno, da mesma forma que as soluções de cipermetrina e deltametrina. As soluções foram mantidas em geladeira a $4{ }^{\circ} \mathrm{C}$ por um período máximo de 1 mês.

Para eliminar resquícios de água dos extratos foi empregado sulfato de sódio anidro (Mallinckrodt). Os adsorventes Florisil (J.B. Baker), Sílica gel (Merck), 230-400 mesh, $C_{18}$ (PR Cola) foram condicionados com acetonitrila e secos em dessecador.

\section{Amostras de manteiga}

Para otimização e validação da técnica de dispersão de matriz em fase sólida e purificação em baixa temperatura foram utilizadas amostras adquiridas no comércio de Viçosa (MG, Brasil), em cujos extratos não foram detectados os piretroides estudados. As amostras foram mantidas em geladeira até o momento de serem utilizadas.

Para otimização da metodologia, amostras de manteiga, $0,50 \mathrm{~g}$, foram aquecidas $\mathrm{a} 50^{\circ} \mathrm{C}$ até se tornarem líquidas. À mistura líquida foram acrescentados $10,0 \mu \mathrm{L}$ de solução padrão contendo os princípios ativos: cipermetrina e deltametrina em uma concentração de 500,0 $\mathrm{mg} \mathrm{L}^{-1}$, obtendo-se uma amostra de $10 \mu \mathrm{g} \mathrm{g}^{-1}$. Depois de homogeneizada a amostra foi mantida à temperatura do ambiente até solidificar.

\section{Análise cromatográfica}

As análises dos extratos orgânicos foram realizadas em cromatógrafo a gás Shimadzu, GC - 17 A, equipado com um detector por captura de elétrons (ECD). Os analitos foram separados utilizando uma coluna capilar Agilent Technologies - HP-5 com fase estacionária composta de $5 \%$ de fenil e $95 \%$ de dimetilpolissiloxano, $30 \mathrm{~m}$ de comprimento; $0,25 \mathrm{~mm}$ de diâmetro interno e $0,1 \mu \mathrm{m}$ de espessura de filme. As condições de trabalho foram: temperatura do injetor $280^{\circ} \mathrm{C}$, temperatura do detector $300{ }^{\circ} \mathrm{C}$ e, vazão do gás de arraste nitrogênio $1,2 \mathrm{~mL} / \mathrm{min}$. A programação de temperatura para aquecimento do forno foi inicialmente $250{ }^{\circ} \mathrm{C}$ com aumento de $10{ }^{\circ} \mathrm{C} \mathrm{min}-1$ até 280 ${ }^{\circ} \mathrm{C}$, permanecendo nesta temperatura por 4 min. ${ }^{8}$ Volume injetado $1,0 \mu \mathrm{L}$, com divisão de fluxo 1:5. Tempo total de análise de $7 \mathrm{~min}$.

\section{Procedimento de extração}

Para cada amostra, foi preparado um branco para avaliar a possível presença dos piretroides estudados e/ou outros interferentes, que poderiam influenciar na etapa de quantificação.

Nas amostras fortificadas e nos brancos de manteiga $(0,50 \mathrm{~g})$ foi adicionada uma quantidade de adsorvente (Sílica, Florisil ou C18). As misturas homogeneizadas foram tratadas com $2,0 \mathrm{~mL}$ de água destilada e $8,0 \mathrm{~mL}$ de solvente extrator e submetidas a um banho ultrassônico por $5 \mathrm{~min}$. Em seguida, foram colocadas em um freezer a $-20{ }^{\circ} \mathrm{C}$ por no mínimo $6 \mathrm{~h}$. A fração congelada, constituída de matriz e água, foi separada do sobrenadante e descartada. O sobrenadante, contendo o solvente extrator e os piretroides, foi filtrado em $\mathrm{Na}_{2} \mathrm{SO}_{4}$. Ao filtrado foram adicionados $0,10 \mathrm{~mL}$ de bifentrina como padrão interno a uma concentração de $50,0 \mathrm{mg} \mathrm{L}^{-1}$, aferindo-se o volume com acetonitrila para $10,0 \mathrm{~mL}$. Os extratos foram armazenados em geladeira até o momento da análise cromatográfica. Todos os ensaios foram realizados em triplicata.

\section{Otimização univariada dos parâmetros de extração}

\section{Adsorvente}

No intuito de avaliar a eficiência dos adsorventes Sílica, Florisil e C18 na adsorção dos piretroides estudados, 0,50 g de adsorvente foram fortificados com $10,0 \mu \mathrm{L}$ de solução contendo os princípios ativos: cipermetrina e deltametrina em uma concentração de 500,0 $\mathrm{mg} \mathrm{L}^{-1}$. Os adsorventes fortificados foram submetidos à extração com 2,0 mL de água destilada e $8,0 \mathrm{~mL}$ de acetonitrila seguindo o procedimento de extração. $\mathrm{O}$ adsorvente que apresentou melhor eficiência foi utilizado nas demais etapas de otimização.

\section{Proporção entre amostra e adsorvente}

Foram realizados testes para estabelecer a proporção ideal entre amostra e quantidade do adsorvente, que proporcionasse maior porcentagem de extração dos piretroides em manteiga e que reduzisse a presença de interferentes da matriz. Dessa maneira, variando apenas a quantidade de adsorvente em relação à amostra, três ensaios foram realizados adicionando-se 0,50; 1,00 e 1,50 g do adsorvente selecionado na etapa anterior, a $0,50 \mathrm{~g}$ de amostra de manteiga fortificada. Em seguida, as amostras foram submetidas à extração com 2,0 mL de água destilada e $8,0 \mathrm{~mL}$ de acetonitrila. Após $5 \mathrm{~min}$ de sonicação a mistura foi levada ao freezer, seguindo o procedimento de extração. A melhor proporção entre amostra e adsorvente foi utilizada nas próximas etapas.

\section{Solvente extrator \\ Acetonitrila e acetato de etila}

Para avaliar a proporção de solvente extrator ideal, amostras de manteiga fortificadas foram misturadas ao adsorvente na proporção estabelecida anteriormente. Após esse procedimento, adicionaram-se às amostras 2,0 mL de água destilada e $8,0 \mathrm{~mL}$ de um solvente extrator. Foram avaliados como solvente extrator as misturas acetonitrila e acetato de etila, nas proporções 6,5:1,5 e 6,0:2,0.

\section{Volume de água}

Com o objetivo de avaliar o volume de água destilada a ser adicionada à matriz, amostras de manteiga fortificadas foram misturadas com o adsorvente e colocadas em contato com 1,0 e 2,0 mL de água destilada e $8,0 \mathrm{~mL}$ do solvente extrator otimizado anteriormente.

\section{Validação do método otimizado para a extração de piretroides em manteiga}

Para assegurar a confiabilidade dos resultados do método de extração otimizado, as figuras de mérito linearidade, seletividade, limites de detecção e quantificação, precisão e exatidão foram determinadas conforme recomendação de agências regulatórias brasileiras ${ }^{13,14} \mathrm{e}$ de publicações relacionadas. . $^{15,16}$

O método otimizado e validado foi aplicado para determinação dos piretroides em amostras de manteiga adquiridas aleatoriamente em quatro estabelecimentos comerciais da cidade de Viçosa - MG. As amostras foram estocadas no freezer à $-20^{\circ} \mathrm{C}$ por um período máximo de $48 \mathrm{~h}$ até o momento da análise.

\section{RESULTADOS E DISCUSSÃO}

\section{Análise cromatográfica}

Um cromatograma de uma solução padrão de $500,0 \mu \mathrm{g} \mathrm{L}^{-1}$ de 
cipermetrina e deltametrina está representado na Figura 2. O tempo total de análise foi de $7 \mathrm{~min}$. O pico 1, com tempo de retenção $\left(t_{R}\right) 2,40$ min corresponde ao padrão interno, bifentrina, os picos de número 2 , entre 3,61 a 3,64 min, correspondem à cipermetrina e seus isômeros e os picos $3 a$ e $3 b$, de $t_{R}$ 4,64 e 4,83 min respectivamente, são picos atribuídos à deltametrina e seus isômeros.

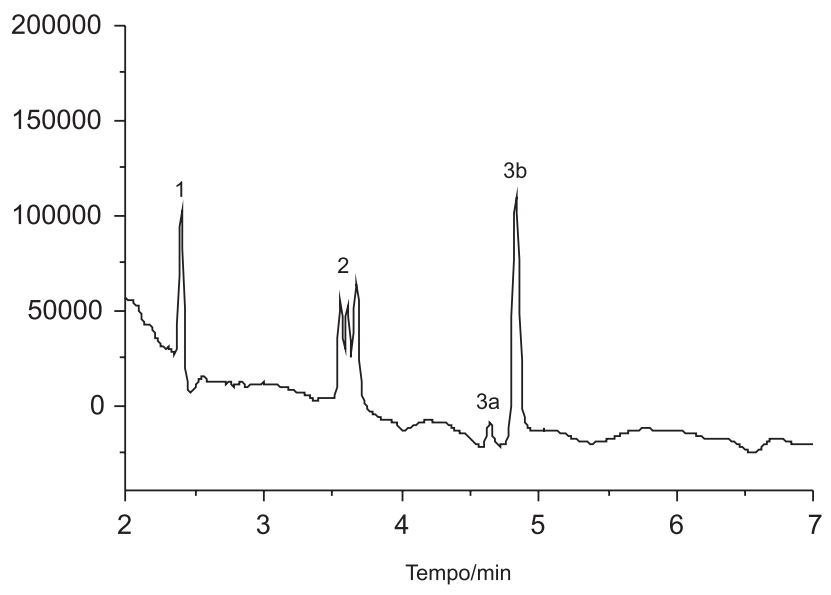

Figura 2. Cromatograma representativo de uma solução padrão de $500 \mu \mathrm{g}$ $L^{-1}$ dos piretroides estudados, onde: pico $1 t_{R}=2,40$ min:bifentrina (padrão interno), pico $2 t_{R}=4,64$ a 4,83 min:cipermetrina e pico $3 t_{R}=4,6$ e 4,8 min:deltametrina

A presença de picos duplos para os piretroides está relacionada com a conversão destes em seus isômeros durante a injeção no cromatógrafo. ${ }^{17}$ Os piretroides $\alpha$-ciano substituídos com um anel ciclopropano, como a cipermetrina e deltametrina, contêm três átomos de carbono assimétricos (centros quirais) podendo existir potencialmente oito estereoisômeros em suas moléculas. Esses estereoisômeros podem ser observados em análises por CG. ${ }^{17}$ Como não era de interesse a determinação isolada dos isômeros dos piretroides, os parâmetros cromatográficos foram selecionados com o objetivo de avaliar os piretroides considerando-se para a quantificação a soma das áreas dos picos de interesse e de seus isômeros correspondentes.

A Figura 3B apresenta um cromatograma típico de um extrato de manteiga fortificada com os piretroides deltametrina e cipermetrina a uma concentração de $10 \mu \mathrm{g} \mathrm{g}{ }^{-1}$.

\section{Otimização dos parâmetros de extração}

Em estudos preliminares, foi observado que o método de extração sólido-líquido e purificação em baixa temperatura (ESL-PBT) em amostras de manteiga não apresentavam a mesma eficiência da técnica usada por Goulart et $a l .^{8}$ em leite. Os extratos obtidos mostraram a presença de interferentes como materiais gordurosos, os quais poderiam danificar a coluna cromatográfica. Embora os extratos, na temperatura ambiente, se mostrassem límpidos, o cromatograma apresentava vários picos que comprometiam a análise cromatográfica. Ao resfriar o extrato em freezer observaram-se pequenos sólidos em suspensão que não foram eliminados no processo de extração.

Para melhorar as características do extrato, incluiu-se um adsorvente (Sílica, Florisil ou C18) na etapa de preparo de amostra semelhantemente à técnica dispersão de matriz em fase sólida. Esse dispersante foi incorporado à matriz pastosa e essa mistura foi então submetida à extração sólido-líquido e purificação em baixa temperatura. Alguns parâmetros do método foram otimizados.

\section{Adsorvente}

Os resultados dos ensaios realizados com o objetivo de selecionar um adsorvente ideal para extração dos piretróides em manteiga são mostrados na Tabela 1 .

Tabela 1. Porcentagem de recuperação (\%R) e coeficiente de variação, $\mathrm{CV}$ (\%), obtidos após contaminação dos adsorventes com os piretroides em concentração de $10 \mu \mathrm{g} \mathrm{g}^{-1}(\mathrm{n}=3)$

\begin{tabular}{lcccc}
\hline \multirow{2}{*}{ Adsorvente } & \multicolumn{2}{c}{ Cipermetrina } & \multicolumn{2}{c}{ Deltametrina } \\
& $\% \mathrm{R}$ & $\mathrm{CV}(\%)$ & $\% \mathrm{R}$ & $\mathrm{CV}(\%)$ \\
\hline Sílica & 57,3 & 9,0 & 75,3 & 3,0 \\
Florisil & 54,1 & 3,4 & 67,4 & 5,4 \\
$\mathrm{C}_{18}$ & 27,9 & 12,4 & 26,3 & 7,0 \\
\hline
\end{tabular}

Independente do adsorvente utilizado foi obtida uma baixa porcentagem de extração dos analitos. Entretanto, observa-se que a sílica apresentou melhores porcentagens de extração e o C18 as menores, o que pode ser explicado pela polaridade e afinidade desses adsorventes pelos analitos. Em função desses resultados, a sílica, apesar de reter parcialmente os analitos foi utilizada nos testes seguintes.

\section{Proporção entre amostra e adsorvente}

Uma vez selecionado o adsorvente, foram realizados testes para estabelecer a proporção ideal entre amostra e adsorvente, que proporcionasse maior porcentagem de extração dos piretroides em manteiga. Na Tabela 2 estão apresentadas as proporções estudadas entre manteiga:sílica e os resultados obtidos.

Tabela 2. Porcentagem de recuperação (\%R) e coeficiente de variação, $\mathrm{CV}$ (\%), obtidos da extração dos piretroides de amostras de manteiga fortificadas $\left(10 \mu \mathrm{g} \mathrm{g}^{-1}\right)$ empregando diferentes proporções entre amostra e adsorvente $(\mathrm{n}=3)$

\begin{tabular}{lcccc}
\hline \multirow{2}{*}{$\begin{array}{l}\text { Proporção } \\
\text { manteiga:sílica }\end{array}$} & \multicolumn{2}{c}{ Cipermetrina } & \multicolumn{2}{c}{ Deltametrina } \\
\hline $1: 1$ & 62,6 & $\mathrm{CV}(\%)$ & $\% \mathrm{R}$ & $\mathrm{CV}(\%)$ \\
$1: 2$ & 34,0 & 20,3 & 81,6 & 17,7 \\
$1: 3$ & 14,2 & 0,0 & 1,8 & 20,8 \\
\hline
\end{tabular}

A proporção 1:1 foi a que apresentou melhor eficiência de extração para os piretroides estudados. Segundo Ribani et al. ${ }^{15}$ são aceitos coeficientes de variação de até $20 \%$ para amostras complexas. Os resultados sugerem que um aumento na quantidade de sílica leva a uma maior adsorção dos princípios ativos, diminuindo, consequentemente, a eficiência da extração.

\section{Solvente extrator}

\section{Acetonitrila e acetato de etila}

Foram realizados ensaios empregando como solvente extrator acetonitrila e acetato de etila na proporção de 6,5:1,5 e 6,0: 2,0. $\mathrm{O}$ valor máximo de acetato de etila que pode ser adicionado à mistura água:acetonitrila sem romper a fase única é de 2,0 mL. $\mathrm{O}$ acetato de etila é menos polar que a acetonitrila e sua adição favoreceu a extração desses princípios ativos. A mistura de 6,0 $\mathrm{mL}$ de acetonitrila e 2,0 $\mathrm{mL}$ de acetato de etila apresentou maior eficiência de extração para os piretroides em manteiga, obtendo-se porcentagens de extração de $105,5 \%$ para cipermetrina e $102,4 \%$ para deltametrina, enquanto que para a mistura contendo $1,5 \mathrm{~mL}$ de acetato de etila a eficiência ficou em torno de $80 \%$ para ambos os piretroides. 
Água

A adição de água à mistura extratora permitiu que a matriz e o adsorvente se congelassem de maneira mais homogênea evitando a presença de material em suspensão, melhorando a resposta da análise cromatográfica. Empregando maior volume de água (2,0 $\mathrm{mL}$ ) foram obtidas porcentagens de extração para a cipermetrina e deltametrina próximas de $95 \%$, sendo este volume adotado no protocolo experimental.

\section{Método otimizado}

O método otimizado consistiu em dispersar $0,50 \mathrm{~g}$ de manteiga em $0,50 \mathrm{~g}$ de sílica gel condicionada e tratar a mistura com 2,0 $\mathrm{mL}$ de água destilada, $6,0 \mathrm{~mL}$ de acetonitrila e $2,0 \mathrm{~mL}$ de acetato de etila. A mistura foi levada a um banho ultrassônico por 5 min e, posteriormente, deixada no freezer a $-20{ }^{\circ} \mathrm{C}$ por no mínimo $6 \mathrm{~h}$. Após esse período foram formadas duas fases: uma fase congelada contendo a fração aquosa e os resíduos sólidos da matriz e uma fase líquida contendo o solvente extrator e os analitos de interesse. A fase líquida sobrenadante foi passada por um funil contendo $1,50 \mathrm{~g}$ de $\mathrm{Na}_{2} \mathrm{SO}_{4}$ anidro. A fração congelada foi descartada e o filtrado recuperado em balão volumétrico de $10,0 \mathrm{~mL}$. Adicionou-se $0,10 \mathrm{~mL}$ de solução padrão de bifentrina a $50,0 \mathrm{mg} \mathrm{L}^{-1}$, aferindo o volume final com acetonitrila.

\section{Validação do método}

Com o objetivo de validar as metodologias de extração e análise de piretroides em leite e manteiga alguns parâmetros foram avaliados seguindo as recomendações da ANVISA ${ }^{13} \mathrm{e}$ de Ribani et al. ${ }^{15}$

\section{Linearidade}

Determinou-se a linearidade de resposta do detector injetando os padrões dos piretroides em acetonitrila em concentrações crescentes de 100,0 a $1000,0 \mu \mathrm{g} \mathrm{L}^{-1}$ com adição da bifentrina como padrão interno. A linearidade de resposta do detector foi avaliada pelo coeficiente de correlação entre a resposta do detector e as concentrações dos piretroides.

Os dados submetidos à análise por regressão linear resultaram em curvas analíticas com equações e os coeficientes de correlação (r) apresentados na Tabela 3.

Tabela 3. Equações das retas e coeficientes de correlação (r) obtidos para os piretroides estudados

\begin{tabular}{lccc}
\hline Piretroide & $\begin{array}{c}\text { Coeficiente } \\
\text { angular }\end{array}$ & $\begin{array}{c}\text { Coeficiente } \\
\text { linear }\end{array}$ & $\begin{array}{c}\text { Coeficiente } \\
\text { de correlação }\end{array}$ \\
\hline Cipermetrina & 0,00311 & $-0,00615$ & 0,99619 \\
Deltametrina & 0,00438 & 0,21467 & 0,99756 \\
\hline
\end{tabular}

Os coeficientes de correlação para os dois piretroides apresentaram valores muito próximos de 1 , o que revela uma relação linear entre as duas variáveis. O critério mínimo aceitável pela ANVISA ${ }^{13}$ deve ser de 0,99 , o que indica uma menor dispersão dos pontos e incerteza dos coeficientes obtidos.

\section{Seletividade}

A seletividade do método de análise dos piretroides em manteiga foi avaliada comparando-se os cromatogramas de extratos de uma matriz de manteiga isenta dos piretroides cipermetrina e deltametrina com extratos de uma matriz fortificada com os mesmos. Comparandose os cromatogramas mostrados na Figura 3 observa-se que nenhum interferente com resposta próxima ao tempo de retenção dos compostos estudados foi detectado.

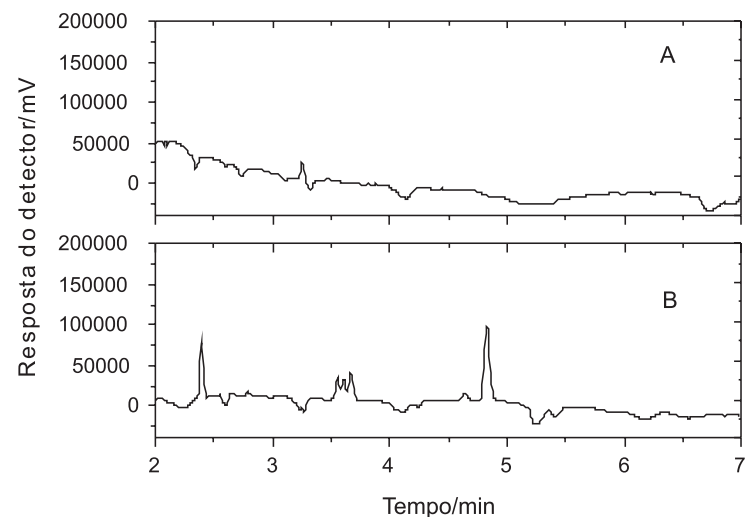

Figura 3. $A$ = Cromatograma de um extrato obtido de uma matriz de manteiga isenta dos piretroides e $B=$ cromatograma de um extrato obtido de uma matriz de manteiga fortificada $\left(10 \mu \mathrm{g} \mathrm{g}^{-1}\right)$ com piretroides, onde: pico $1 t_{R}=$ 2,4 min:padrão interno, bifentrina; pico $2 t_{R}=3,6$ a 3,7 min:cipermetrina $e$ pico $3 t_{R}=4,6$ e 4,82 min:deltametrina

Limite de detecção $(L D)$ e limite de quantificação $(L Q)$ do método de extração líquido-líquido e partição em baixa temperatura

Os limites de detecção e quantificação foram obtidos pelas equações de regressão em que foram relacionadas às respostas do detector com as concentrações dos princípios ativos nas amostras fortificadas.

Uma das maneiras de calcular o limite de detecção (LD) é pelos parâmetros da curva analítica, ${ }^{14}$ dada pela razão entre os coeficientes linear e angular multiplicada por 3,3. Observou-se então que a quantidade mínima detectável para a cipermetrina foi de $0,082 \mu \mathrm{g} \mathrm{g}^{-1}$ e para a deltametrina, $0,11 \mu \mathrm{g} \mathrm{g} \mathrm{g}^{-1}$.

Semelhante ao LD, o limite de quantificação (LQ) foi calculado pela razão entre os coeficientes linear e o angular, mas multiplicada por 10. Verificou-se que para a cipermetrina o valor encontrado foi de $0,28 \mu \mathrm{g} \mathrm{g}^{-1}$ e para a deltametrina, $0,32 \mu \mathrm{g} \mathrm{g}^{-1}$.

\section{Precisão \\ Repetitividade}

A precisão foi avaliada pelo coeficiente de variação dos resultados de nove repetições do método de extração e análise dos piretroides em amostras de manteiga fortificadas com $10 \mu \mathrm{g} \mathrm{g}^{-1}$ de amostra. Obteve-se um coeficiente de variação de $2,9 \%$ para a cipermetrina e $2,1 \%$ para a deltametrina. Os valores encontrados estão dentro do permitido (20\%) para amostras complexas..$^{13,15}$

\section{Precisão intermediária}

A precisão intermediária foi realizada, aplicando-se o método otimizado em amostras de manteiga fortificadas a $10 \mu \mathrm{g} \mathrm{g}^{-1} \mathrm{de}$ amostra, em triplicata, em três dias diferentes ( $1^{\circ}, 7^{\circ}$ e e $30^{\circ}$ dia). Os ensaios foram realizados no mesmo laboratório, pelo mesmo analista nas mesmas condições de extração e análise. A precisão intermediária foi avaliada pela porcentagem de recuperação, desvio padrão, coeficientes de variação obtidos em cada ensaio. Os resultados apresentados na Tabela 4 mostram uma boa precisão do método proposto com coeficientes de variação inferiores a $6 \%$.

\section{Exatidão}

Para avaliar a exatidão do método, os piretroides foram adicionados para obter amostras de concentrações iguais a 1,0;1,5 e 2,0 $\mu \mathrm{g}$ $\mathrm{g}^{-1}$. Os resultados obtidos para extração dos piretroides cipermetrina e deltametrina, bem como os respectivos coeficientes de variação estão apresentados na Tabela 5.

Os resultados mostram que, independente do nível de concentra- 
Tabela 4. Porcentagens de recuperação $(\% \mathrm{R})$ e coeficientes de variação, $\mathrm{CV}(\%)$, dos piretroides cipermetrina e deltametrina, de amostras de manteiga fortificadas com $10 \mu \mathrm{g} \mathrm{g}^{-1}$, usando o método otimizado em diferentes dias $(\mathrm{n}=9)$

\begin{tabular}{lcccc}
\hline & \multicolumn{2}{c}{ Cipermetrina } & \multicolumn{2}{c}{ Deltametrina } \\
& $\% \mathrm{R}$ & $\mathrm{CV}(\%)$ & $\% \mathrm{R}$ & $\mathrm{CV}(\%)$ \\
\hline 1 dia & 96,0 & 2,9 & 85,6 & 2,5 \\
1 semana & 95,6 & 4,6 & 86,8 & 5,2 \\
1 mês & 96,1 & 1,4 & 97,3 & 5,5 \\
\hline
\end{tabular}

Tabela 5. Porcentagens de recuperação $(\% \mathrm{R})$ e coeficientes de variação, $\mathrm{CV}(\%)$, dos piretroides cipermetrina e deltametrina, de amostras de manteiga fortificadas em diferentes concentrações aplicando o método otimizado $(n=3)$

\begin{tabular}{lcccc}
\hline Concentração da amostra & \multicolumn{2}{c}{ Cipermetrina } & \multicolumn{2}{c}{ Deltametrina } \\
\hline$\left(\mu \mathrm{g} \mathrm{g}^{-1}\right)$ & $\% \mathrm{R}$ & $\mathrm{CV}(\%)$ & $\% \mathrm{R}$ & $\mathrm{CV}(\%)$ \\
1,0 & 96,7 & 9,1 & 89,5 & 8,7 \\
1,5 & 94,6 & 8,5 & 85,2 & 5,8 \\
2,0 & 94,9 & 5,9 & 95,9 & 4,9 \\
\hline
\end{tabular}

ção dos analitos na amostra, a extração dos piretroides em manteiga é eficiente apresentando coeficientes de variação inferiores a $10 \%$.

Avaliação da presença de resíduos de piretroides nas amostras de manteiga comercializadas em Viçosa

Depois de validado o método foi aplicado a 3 amostras de manteiga adquiridas aleatoriamente no comércio de Viçosa, MG. Entretanto em nenhuma das amostras foi detectada a presença de resíduos dos piretroides deltametrina e cipermetrina, apesar do método proposto apresentar sensibilidade suficiente para detectar resíduos em níveis inferiores ao limite máximo estabelecido pela legislação internacional para leite. De acordo com World Health Organization e o Codex Alimentarius, o limite para piretroides em leite é de 0,01 e $0,05 \mu \mathrm{g}$ $\mathrm{g}^{-1}$, respectivamente. ${ }^{18-20}$ Até o momento, não há um limite máximo de resíduos estabelecido para amostras de manteiga.

\section{CONCLUSÕES}

A associação das técnicas de extração DMFS e ESL-PBT para determinação de piretroides em manteiga resultou em um método simples e eficaz, consumindo uma pequena quantidade de amostra e de solvente extrator, com porcentagens de recuperação elevadas. Nesta técnica, a escolha do adsorvente e do solvente extrator foi avaliada em função das características dos piretroides. Adsorventes mais polares, como a sílica, associados a solventes menos polares, como a mistura acetonitrila e acetato de etila, contribuíram para aumentar a eficiência da extração de agrotóxicos hidrofóbicos.

\section{AGRADECIMENTOS}

Ao CNPq e à FAPEMIG pelo apoio financeiro.

\section{REFERÊNCIAS}

1. Michaelidou, A. M.; Small Rumin. Res. 2008, 79, 42.

2. Ciscato, C. C. H. P.; Gebara, A. B.; Spinosa, H. S.; Pesticidas: Rev. Ecotoxicol. Meio Amb. 2004, 14, 25.

3. Bressan. M.; Práticas de manejo sanitário em bovinos de leite, Embrapa Gado de Leite: Juiz de Fora, 2000.

4. Muccio, A.; Pelosi, P.; Barbini, D. A.; Generali, T.; Ausili, A.; Vergori, F.; J. Chromatogr., A 1997, 765, 51.

5. Goulart, S. M.; Dissertação de Mestrado, Universidade Federal de Viçosa, Brasil, 2004.

6. Gilbert-López, B.; García-Reyes, J. F.; Molina-Díaz, A.; Talanta 2009, 79, 109.

7. Beyer, A.; Biziuk, M.; Food Chem. 2008, 108, 669.

8. Goulart, S. M.; Queiroz, M. E. L. R.; Neves, A. A.; Queiroz, J. H.; Talanta 2008, 75, 1320.

9. Mcculley, K. A.; Mckinley, W. P.; J. Assoc. Off. Anal. Chem. 1964, 652.

10. Vieira, H. P.; Neves, A. A.; Queiroz, M. E. L. R.; Quim. Nova 2007, 30, 535.

11. Pinho, G. P.; Neves, A. A.; Queiroz, M. E. L. R.; Quim. Nova 2009, 32, 92.

12. Bogialli, S.; Di Corcia, A.; J. Biochem. Biophys. Methods 2007, 70, 163.

13. Agência Nacional de Vigilância Sanitária (ANVISA); Guia para Validação de Métodos Analíticos e Bioanalíticos, Resolução RE $n^{o} .899$, de 29/05/2003.

14. Instituto Nacional de Metrologia, Normalização e Qualidade Industrial (INMETRO); Orientações sobre Validação de Métodos de Ensaios Químicos, DOQ-CGCRE-008, 2007.

15. Ribani, M.; Bottoli, C. B. G.; Collins, C. H.; Jardim, I. C. S. F.; Melo, L. F. C.; Quim. Nova 2004, 27, 771.

16. Lanças, F. M.; Validação de métodos cromatográficos de análise Métodos Cromatográficos de Análise 6, Ed. Rima: São Carlos, 2004.

17. Maštovská, K.; Lehotay, S. J.; J. Chromatogr., A 2004, 1040, 259.

18. World Health Organization (WHO); Environmental Health Criteria 82. Cypermethrin, Genebra, 1990.

19. World Health Organization (WHO); Environmental Health Criteria 97. Deltamethrin, Genebra, 1990.

20. CODEX ALIMENTARIUS; http://www.codexalimentarius.net/mrls/ pestdes/jsp/pest_q-e.jsp, acessada em Abril 2010. 